\title{
Ecological and environmental predictors of escape among birds on a large tropical island
}

\author{
Kasun B. Ekanayake ${ }^{1,2}$. Jonathan Jebamaithran Gnanapragasam ${ }^{1} \cdot$ Kithsiri Ranawana $^{3}$. \\ Dulan Ranga Vidanapathirana $^{4} \cdot$ U. Tiran Abeyawardhana ${ }^{5}$. Chandima Fernando ${ }^{6}$. Alexandra McQueen ${ }^{1}(D)$ \\ Michael A. Weston ${ }^{1}$ (D) Matthew R. E. Symonds ${ }^{1}$ (D)
}

Received: 18 November 2021 / Revised: 19 January 2022 / Accepted: 21 January 2022 / Published online: 10 February 2022

(c) The Author(s) 2022

\begin{abstract}
Ecological and environmental traits can influence avian escape behaviour but most data underpinning our current understanding relates to continental and temperate areas and species. We conducted a phylogenetically controlled comparative analysis of flight-initiation distance (FID) against a variety of environmental, behavioural and life history attributes for Sri Lankan birds (202 species; $n=2540$ ). As with other studies, body mass was positively associated with FID, and longer FIDs occurred in areas where human population density was lower. We also found that the effect of human population density was more pronounced in larger birds. Birds that were in groups when approached tended to have longer FIDs. Unlike the findings of other comparative analyses, based mostly on continental, temperate populations, most other ecological variables did not feature in the best models predicting FID (time of year, breeding system, clutch size, habitat, migratory behaviour, development [altricial/precocial], elevation and diet). Thus, some associations (body mass and exposure to humans) may be universal, while others may not manifest themselves among tropical avifaunas. Further tropical datasets are required to confirm truly universal associations of environmental and ecological attributes and escape distances among birds.
\end{abstract}

\section{Significance statement}

Escape responses in birds are influenced by the environment in which they live, the conditions under which they face a threat and their own biological characteristics. The vast majority of our knowledge of avian escape behaviour is derived from continental, temperate species. We examined the environmental and ecological factors that shape flight-initiation distance (FID), the distance at which a bird reacts to an approaching threat (a walking human) by escaping, using 2540 observations of 202 bird species on a large tropical island-Sri Lanka. Several predictors of FIDs in birds are clearly influential for Sri Lankan birds: body mass, human population density and whether the bird is alone or in as group. However, many other putative predictors are not, suggesting that tropical island avifaunas may have different responses to approaching threats compared to their temperate continental counterparts.

Keywords Body mass · Comparative analysis $\cdot$ Flight-initiation distance $\cdot$ Group size $\cdot$ Human density $\cdot$ Sri Lanka

\section{Introduction}

Communicated by P. A. Bednekoff

Kasun B. Ekanayake and Jonathan Jebamaithran Gnanapragasam are joint first authors.

Michael A. Weston and Matthew R.E. Symonds are joint senior authors

Matthew R. E. Symonds

matthew.symonds@deakin.edu.au

Extended author information available on the last page of the article
For wildlife, escape from predators is a critical part of survival, and is associated with a variety of ecological and environmental traits (Blumstein 2006; Møller 2014). Flightinitiation distance (FID), the distance at which animals commence escape from an approaching threat, potentially constitutes a general proximate measure influencing ecological and life history trade-offs and reflects the risks that individuals take when responding to a putative predator. A plethora of comparative studies have mapped prominent associations 
between avian FIDs and ecological, environmental and contextual variables (Blumstein 2019). Among birds, life history influences the FIDs of individuals (Møller 2014) and life and natural history traits influence FIDs across species (Blumstein 2006). Environmental factors are also prominent in terms of their association with FIDs (Blumstein 2006; Samia et al. 2015a), with some factors potentially being universal mediators of FID.

Most comparative FID studies of birds report a positive association between FID and body mass across species, with larger birds having longer FIDs (see Weston et al. 2012). This might be due to lower agility and speed of escape (Blumstein 2006), and/or because larger birds are longer lived, and therefore more risk-averse as they trade off current survival with future reproductive potential (see Weston et al. 2012). Social and developmental contexts are also associated with FIDs (Blumstein 2006). Longer FIDs may occur among birds in groups (perhaps because vigilance may be more effective; Morelli et al. 2019) or for species which breed cooperatively (possibly due to highly coordinated alarm and response among such species; Blumstein 2006). Developmental mode (whether offspring are altricial or precocial) could conceivably influence FID (increased parental investment in young could reduce risk-taking; but see Blumstein 2006), and variation in clutch sizes (reproductive potential, possibly influencing risk-taking) may also be associated with FIDs (Møller and Liang 2013; but see Blumstein 2006). Migratory birds exhibit longer FIDs, perhaps because migratory species have lower familiarity with local environments and risks in comparison with resident species (Mikula et al. 2018a, b) or perhaps because migration is associated with heightened predator risk resulting in adaptations to avoid depredation (Simpson et al. 2015). Omnivorous and carnivorous diets are associated with longer FIDs, suggesting foraging ecology and/or adaptations may also influence FID (Blumstein 2006).

Environmental influences on FID are also apparent. Most comparative analyses of FID report longer response distances in rural compared with urban environments, a difference attributed to exposure to humans (Samia et al. 2015a). Elevation may influence FIDs, with longer FIDs in at least one upland bird (Andrade and Blumstein 2020). Habitat complexity/density may theoretically alter FID with shorter FIDs where more cover exists (Lomas et al. 2014), although some studies report no such effect (Blumstein 2006; OsorioBeristain et al. 2018). Some environmental aspects which influence FIDs may vary temporally. Time of day may influence avian FIDs, perhaps due to energetic constraints early in the day (McQueen et al. 2021), and consequent trade-offs between starvation and predator risk (Moiron et al. 2018). Short FIDs in the morning have been shown for only one bird species, and time of day has been recommended to be included in analyses of FID (Ferguson et al. 2019).
Despite the recent growth in our understanding of associations between ecological and environmental traits, and escape among birds derived from comparative studies (Blumstein 2019), these have been dominated by datasets from continental, temperate areas (predominantly North America, Europe and Australia; e.g. Blumstein 2006), and more recently augmented for avifauna in equatorial mainland Africa (Weston et al. 2021). However, tropical (especially equatorial), non-continental avifaunas remain poorly studied in this regard (Møller and Liang 2013, and Gotanda 2020 are rare exceptions). Climate influences avian life histories, including FIDs, and some of the described life history/FID associations which have been studied may be absent from tropical populations (see Møller and Liang 2013). Avian life histories vary between tropical and temperate birds in many aspects; notably, tropical birds generally experience a greater risk of predation, more stable climate and more disease, and food resources may be more stable (Møller and Liang 2013). Avian FIDs decrease with increasing latitude (Diaz et al. 2013; Poddubnaya et al. 2019), and tropical birds exhibit longer FIDs than sister taxa in temperate areas, a finding attributed to different life histories and predator environments between climatic zones (Møller and Liang 2013). However, general patterns of associations with FIDs, derived from mostly temperate datasets, may not hold in tropical areas. For example, tropical birds may not exhibit lower FIDs in areas with more people (Møller and Liang 2013; Bjørvik et al. 2015; but see Piratelli et al. 2015 and Tryjanowski et al. 2020)— the latter generally being conceived as a possibly universal pattern as reported from mostly temperate, continental datasets (Samia et al. 2015a). This may reflect underlying differences in associations with life history, or the nature of human population density gradients between urban and rural areas, or both between tropical and temperate avifaunas.

Islands hold a disproportionate diversity of birds, and avian life histories are shaped by island isolation (Newton 2003). Unsurprisingly, FID varies between mainland and island vertebrates such as reptiles, mammals and birds, i.e. these taxa exhibit 'island tameness' on predator free islands (Humphrey et al. 1987; St Clair et al. 2010; Cooper et al. 2014; Cabrera et al. 2017). Although Sri Lanka is large and not particularly isolated, such differences may manifest themselves over fairly modest geographical scales. For example, even within one island group, avian FIDs can vary, being longer on islands with introduced predators or those visited infrequently by people (St Clair et al. 2010; Thibault et al. 2020). Thus, comparative analyses involving island avifaunas may reveal new or specific patterns in FID, potentially different from those derived from predominantly continental datasets (Blumstein 2019; Tryjanowksi et al. 2020).

Data on tropical avian FIDs are relatively sparse (Piratelli et al. 2015), and this is especially so of islands, including 
large, near-continental islands. Asia presents a gap in current knowledge of avian FIDs (Blumstein 2019). Here, we use a substantial dataset on FIDs of Sri Lankan birds to examine associations with life and natural history and environmental influences, while controlling for phylogeny and sampling effort. Our aim is to explore associations of available ecological and environmental traits used in existing comparative studies, in the context of a large tropical island avifauna. We compare a broad diversity of Sri Lankan species and present the most comprehensive comparative analysis of FID of a tropical island avifauna available, and the first account of FIDs for Sri Lankan birds in all climatic zones (see Gnanapragasam et al. 2021). Given that tropical islands are under immense conservation pressure, sometimes hosting dense human populations (Qadeer 2000) and substantial nature and ecotourism (d'Hauteserre 2016), documenting response distances may also assist in informing suitable management of human disturbance (Guay et al. 2016).

\section{Methods}

We measured flight-initiation distance (FID), the distance at which birds commence escape from an approaching person, a widely used method of indexing escape behaviour in animals (Blumstein 2003). Observers wore dull pants, shirts and hats. We recorded the distance at which approaches commenced (StDist; starting distance), which is usually positively associated with FID (Blumstein 2003). We sampled singlets or single-species groups. Repeat sampling of individuals was avoided by collecting data at many sites, not resampling the same location, and not sampling the same species $<50 \mathrm{~m}$ from a point at which it had already been sampled. FIDs were recorded in a range of habitats by opportunistically collecting FIDs across as many habitats as could be visited. FIDs for perched birds were corrected for observer height (Livezey and Blumstein 2016), and straight line distances were calculated. Our dataset did not support the use of the Phi Index (Samia and Blumstein 2014), because we could not reliably measure alert distances (see Guay et al. 2013). Note that it was not possible to record data blind because our study involved focal animals in the field.

\section{Ecological and environmental traits}

We extracted 13 ecological and environmental variables which have been previously identified as influencing, or being candidates to influence, avian FIDs (Table 1). Every FID was geolocated, enabling each to be allocated a corresponding elevation, human population density and location (geographically proximate areas that exhibit the same prevailing regimes of human occurrence, land use and activity; $n=124$ locations). Date and time of day were collected along with StDist, for each FID. Other life and natural history traits were derived from the literature (see Table 1) and gaps filled with expert consultation and opinion which extended beyond the authorship team (U. Ekanayake; S. Seneviratne, banding data from Field Ornithological Group of Sri Lanka).

\section{Phylogenetic comparative analysis}

We constructed models of the response of FID to the following predictor variables: starting distance, body mass (for the species), human population density, group status (because these data were highly skewed towards single individuals and estimation of exact group size when with others was often ambiguous, this was categorised as either solitary or with other birds at the time of encounter), time of day, Julian date, elevation (this was clearly bimodally distributed and so was categorically divided into highland sites $>1500 \mathrm{~m}$ and lowland sites $<1000 \mathrm{~m}$ asl), breeding system, habitat type, migratory behaviour, clutch size, developmental type and diet (Table 1). Julian date was circular transformed to convert into radians. To improve normality and reduce skew of distributions, all continuous variables were $\log _{10}$-transformed and $z$-standardised. Finally, we also considered three interaction terms in our modelling: mass $\times$ population density, to account for differences in the way different sized birds might respond to increased human presence (sensu Weston et al. 2021); starting distance $\times$ habitat type, to account for the possibility that starting distance will have different relationships to FID in different habitats (Mayer et al. 2019); and elevation $\times$ migration, to account for possible physiological constraints in escape at higher elevations, between residents and migrants (Barve et al. 2016). Additionally, differential parasite loads may exist in birds between elevations, which may also vary with migration and breeding status (Gonzalez et al. 2014), and could influence escape.

We performed analyses using a Bayesian Markov Chain Monte Carlo phylogenetic generalised linear mixed model approach, using the MCMCglmm package (Hadfield 2010) in $\mathrm{R}$ version 4.0.2 ( $\mathrm{R}$ Core Team 2020). Here, in addition to the fixed effects, species identity was included as a random effect with a phylogenetic structure to control for nonindependence of those species and to control for sampling of multiple individuals from the same species. Location was also included as a random effect to control for repeat sampling from the same locations. By including all individual observations in a phylogenetic comparative analysis, one automatically incorporates within-species variation and differences in sampling (Garamszegi and Møller 2010).

The phylogeny used as the basis for analysis was derived from www.birdtree.org (Jetz et al. 2012); 2000 trees were downloaded for the subset of species from the pseudo-posterior distribution of trees using the 'backbone' phylogeny 


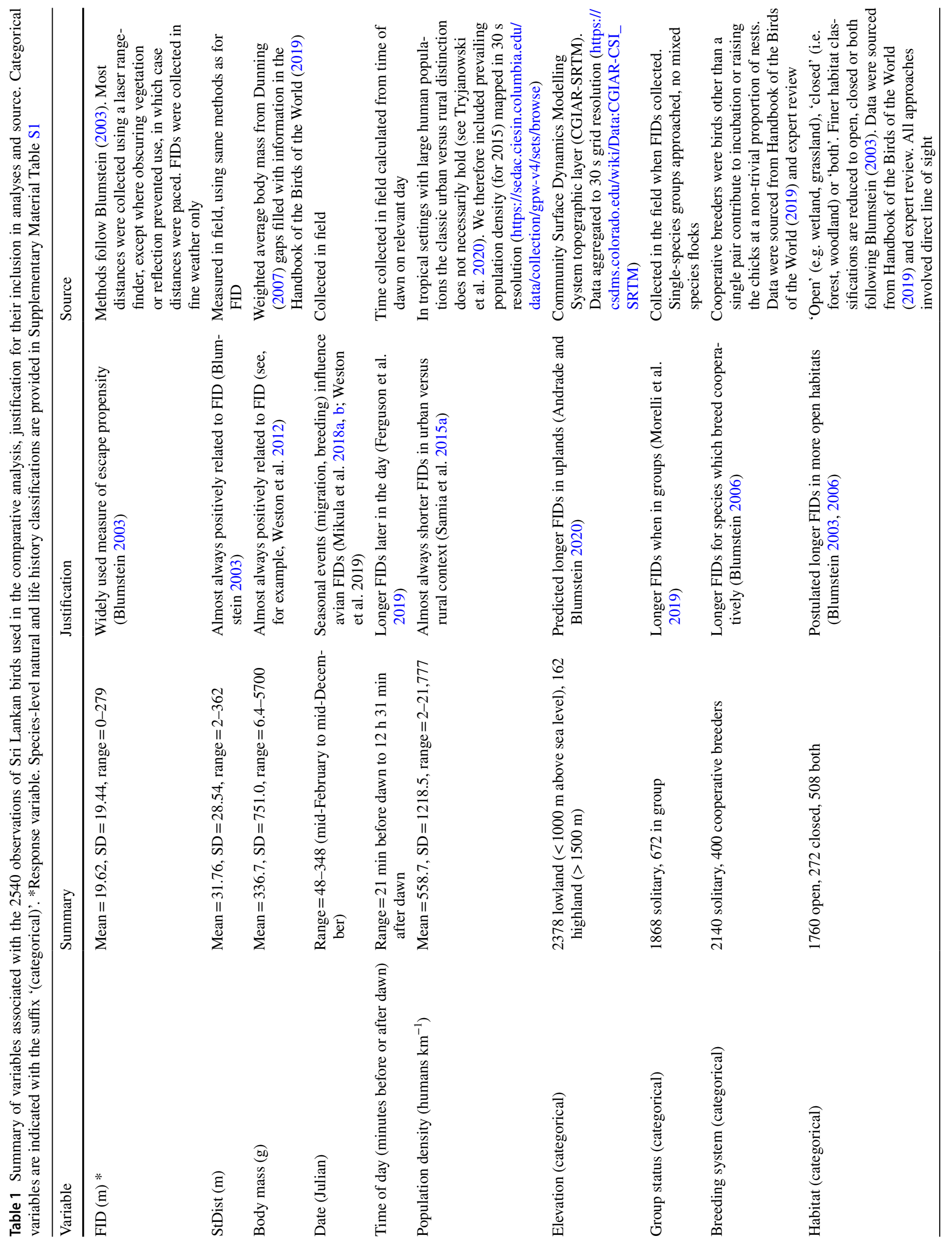




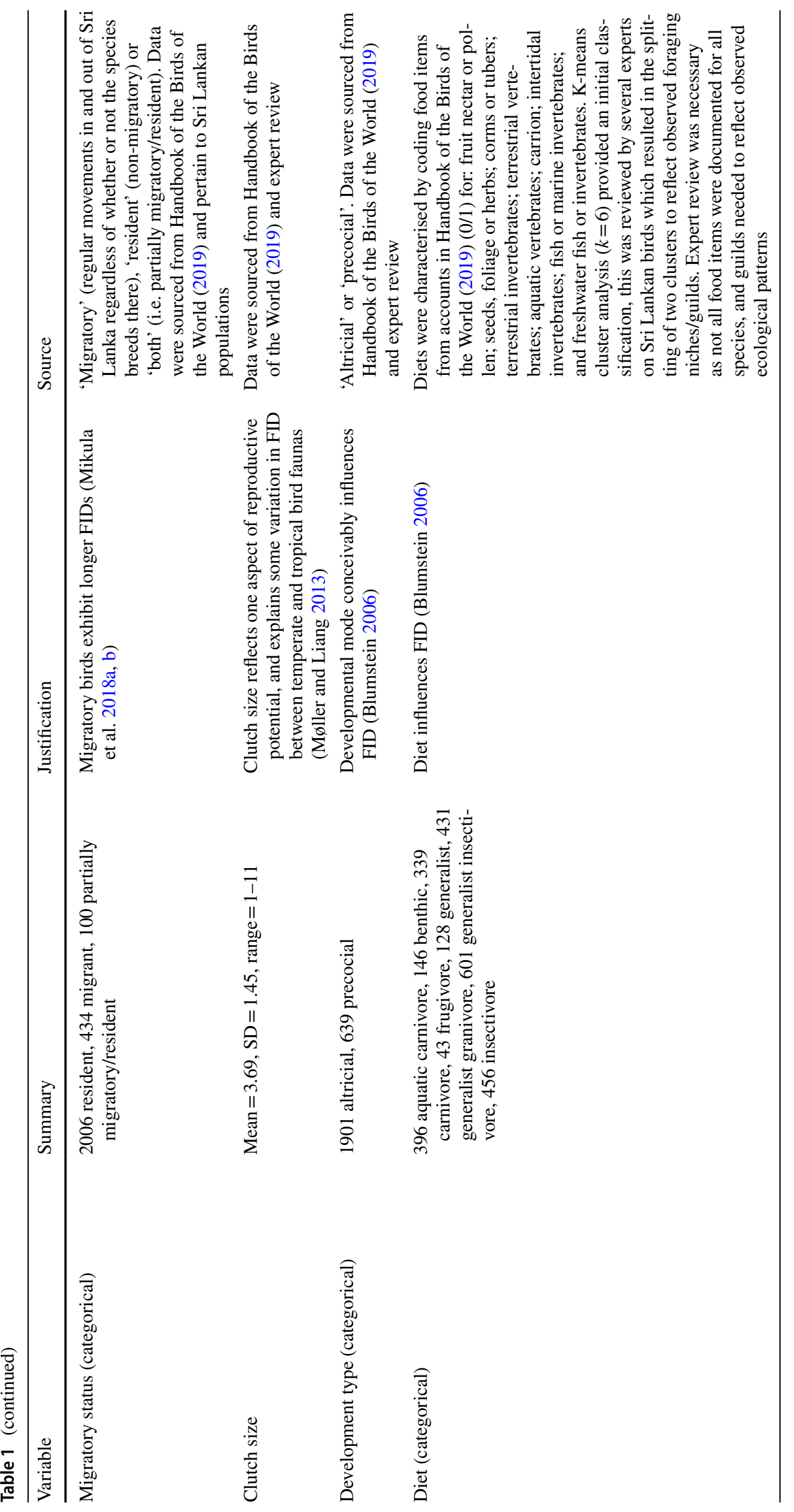


from Hackett et al. (2008). From these 2000 trees, we generated a single maximum clade credibility tree using the maxCladeCred function in the $\mathrm{R}$ package phangorn version 2.7.1 (Schliep 2011).

The priors used for the MCMCglmm analysis were flat, uninformative priors $(V=1, \mathrm{nu}=0.02$, for random terms and residual variance) and the analysis was performed for 101,000 runs with a burn-in of 1000 and a thinning interval of 100, resulting in an effective sample size of the posterior distribution of 1,000 (after the first 1000 'burn-in' runs are discarded, every 100th result is taken from 100,000 remaining runs, making 1000 selected runs in total). Convergence of the runs was confirmed through visual evaluation of convergence (trace) plots. Parameter estimates were then calculated as the means of the estimates in the posterior distribution, with $95 \%$ credibility intervals obtained and pMCMC values being the proportion of iterations in the posterior distribution where the estimate crossed 0 . The extent to which the fixed effects in models described variation in FID was calculated via marginal $R^{2}$ values (Nakagawa and Schielzeth 2013).

We used a model selection approach to determine the most important variables influencing FID in Sri Lankan birds. Top models were selected based on Akaike's information criterion (AIC; Burnham and Anderson 2002) corrected for small sample size (AICc) because, although our sample size is not small, a large number of predictors were included. 'Top models' within delta two AICc of the highest ranked model were selected using the 'dredge' function in the package MuMIn (Barton 2020). We repeated the dredge process for three global models, each including 13 fixed effects (described above) and one of the three interaction terms (i.e. separate models with mass $\times$ population density, starting distance $\times$ habitat and migration $\times$ elevation). To reduce computation time, we fixed the variables 'starting distance' and 'mass' to be included in all models; both of these variables are known to strongly correlate with FIDs from previous studies (see Weston et al. 2012) and had large, statistically significant effects in our full model. We present top selected models from the global model including mass $\times$ population density in our results, as this was the only interaction term that was included in top models (i.e. the interactions starting distance $\times$ habitat and migration $\times$ elevation were not included in the subset of models within $\Delta \mathrm{AICc} \leq 2$ ). The full model was run in the same manner as the three global models described above, but with a larger effective sample size of 10,000 (number of iterations $=401,000$; burn-in $=1000$; thinning interval $=40$, for explanation of how this results in this effective sample size see above).

We checked all fixed predictors in the best models for collinearity through correlation plots (continuous variables only) and variance inflation factors (VIF; all variables) which revealed no significant problems with collinearity between predictors (Pearson's $r \leq 0.4$; VIF $\leq 3$, with the exception of diet, which does not feature in any top models, see the 'Results' section).

\section{Data availability}

A summarised species average dataset is presented in Supplementary Material Table S1. The complete dataset of FID observations and associated location data is available through Dryad (datadryad.org) (Ekanayake et al. 2022).

\section{Results}

We obtained 2,540 observations of flight-initiation distances from 202 species of Sri Lankan birds. The birds represented individuals from a range of environments and with diverse biological and ecological characteristics (Supplementary Material Table S1).

Our model selection approach identified 12 top models whose AIC scores were within 2 units of each other (Table 2). The best approximating model identified starting distance, body mass, human population density and whether the focal bird was alone or in a group, as predictors. Additionally, time of day, and the interaction between body mass and population density, featured prominently in the list of top models. None of the other predictors or interaction terms featured strongly among the best models.

The best approximating model (Table 3 ) identified that, in addition to starting distance, body mass was positively associated with FID, with larger bodied species having longer FIDs (Fig. 1A). Birds that were alone had shorter FIDs compared to those that were associated with other individuals (Fig. 1B). Human population density was negatively associated with FID, with birds responding to an approaching human at shorter distances in areas that have higher population density (Fig. 1C). We also considered the most complex model in the list of top models that contained the other prominent predictors identified above (Table 3 ). This model indicated that birds observed later in the day tended to have longer FIDs (Fig. 1D); however, the effect was minimal, and the credibility intervals on the estimate spanned zero, suggesting it cannot be considered with much confidence. This model did, though, show an interaction effect between mass and population density indicating that larger birds show a steeper decline in FID with increasing population density compared to smaller birds (Fig. 2).

The full global model (Table 4) indicated two further effects where the credibility intervals on the estimates did not cross zero (and pMCMC values were less than 0.05 ). The first of these was elevation, with lowland birds tending to have longer FIDs than those in highland areas. The other (the migratory behaviour:elevation interaction) suggests 
Table 2 Comparison of the generalised linear mixed models predicting flight-initiation distance (FID) in Sri Lankan birds. Variables included are those identified as producing almost equally good top models through model selection: starting distance of the FID approach, mass (average body mass for the species), group status (whether the focal bird was alone or in a group), population density (humans per $\mathrm{km}^{2}$ ) and time (minutes after dawn). All models include location and species (with a phylogenetic framework) as random effects. We present the AICc, delta AICc and marginal $R^{2}$ values for fixed effects

\begin{tabular}{|c|c|c|c|c|}
\hline Model no & Model components & $\mathrm{AICc}$ & $\begin{array}{l}\text { Delta score } \\
(\Delta \text { AIC })\end{array}$ & $R^{2}$ \\
\hline 1 & StDist + mass + group status + population density & 3644.9 & 0.00 & 0.62 \\
\hline 2 & StDist + mass + group status + population density + mass $*$ pop. dens & 3645.3 & 0.40 & 0.62 \\
\hline 3 & StDist + mass + group status + time & 3645.4 & 0.46 & 0.56 \\
\hline 4 & $\begin{array}{l}\text { Starting distance + mass + group status + population den- } \\
\text { sity + time + mass*pop. dens }\end{array}$ & 3645.4 & 0.49 & 0.62 \\
\hline 5 & StDist + mass & 3645.5 & 0.51 & 0.56 \\
\hline 6 & StDist + mass + time & 3645.6 & 0.65 & 0.56 \\
\hline 7 & StDist + mass + population density & 3646.1 & 1.11 & 0.62 \\
\hline 8 & StDist + mass + population density + mass* pop. dens & 3646.1 & 1.19 & 0.62 \\
\hline 9 & StDist + mass + population density + time & 3646.3 & 1.31 & 0.62 \\
\hline 10 & StDist + mass + population density + time + mass $*$ pop. dens & 3646.6 & 1.68 & 0.62 \\
\hline 11 & StDist + mass + group status + population density + time & 3646.8 & 1.90 & 0.62 \\
\hline 12 & StDist + mass + time + migration & 3646.9 & 1.92 & 0.58 \\
\hline
\end{tabular}

Marginal $R^{2}$ for full model $=0.68$

Table 3 Top generalised linear mixed model models predicting flight-initiation distance in Sri Lankan bird species. Shown is the highest ranked model (Model 1 in Table 2) and the model with the greatest number of predictors (Model 4 in Table 2) of the twelve selected 'top' models within $\leq 2 \Delta$ AICc. FID and all continuous predictors were $z$-standardised. Mean estimate and $95 \% \mathrm{CI}$ refer to the mean and $95 \%$ credible interval of the Bayesian posterior distribution obtained using MCMCglmm. $\lambda$ is a measure of the phylogenetic signal in the model residuals (Pagel 1999). The 'group status' estimate applies to focal birds observed while standing alone (without other individuals).

$P$ values show the proportion of the posterior distribution estimated to cross zero

\begin{tabular}{|c|c|c|c|c|}
\hline \multicolumn{5}{|c|}{ Model 1 (highest ranked model; marginal $R^{2}=0.62 ;$ conditional $R^{2}=0.71 ; \lambda=0.11$ ) } \\
\hline Random effects & \multicolumn{4}{|l|}{ Variance } \\
\hline Phylogeny & \multicolumn{4}{|l|}{0.036} \\
\hline Species & \multicolumn{4}{|l|}{0.009} \\
\hline Location & \multicolumn{4}{|l|}{0.036} \\
\hline Residual & \multicolumn{4}{|l|}{0.244} \\
\hline Fixed effects & Post mean & Lower CI & Upper CI & $\mathrm{P}$ \\
\hline Intercept & 0.139 & $2 \times 10^{-4}$ & 0.280 & 0.046 \\
\hline StDist & 0.611 & 0.586 & 0.636 & $<0.001$ \\
\hline Mass & 0.099 & 0.047 & 0.157 & 0.004 \\
\hline Group status (single) & -0.049 & -0.096 & 0.001 & 0.040 \\
\hline Population density & -0.150 & -0.196 & -0.105 & $<0.001$ \\
\hline \multicolumn{5}{|c|}{$\begin{array}{l}\text { Model } 4 \text { (top model with the most variables; marginal } R^{2}=0.62 \text {; conditional } R^{2}=0.71 ; \lambda=0.11 ; \Delta \mathrm{AIC} \\
0.49 \text { ) }\end{array}$} \\
\hline Random effects & Variance & & & \\
\hline Phylogeny & 0.034 & & & \\
\hline Species & 0.009 & & & \\
\hline Location & 0.035 & & & \\
\hline Residual & 0.244 & & & \\
\hline Fixed effects & Post mean & Lower CI & Upper CI & $\mathrm{P}$ \\
\hline Intercept & 0.105 & -0.051 & 0.249 & 0.150 \\
\hline StDist & 0.612 & 0.586 & 0.639 & $<0.001$ \\
\hline Mass & 0.092 & 0.040 & 0.141 & 0.004 \\
\hline Group status (single) & -0.048 & -0.095 & $2 \times 10^{-4}$ & 0.046 \\
\hline Population density & -0.136 & -0.178 & -0.093 & $<0.001$ \\
\hline Time & $1 \times 10^{-4}$ & $-3 \times 10^{-5}$ & $2 \times 10^{-4}$ & 0.182 \\
\hline Mass*population density & -0.039 & -0.062 & -0.014 & $<0.001$ \\
\hline
\end{tabular}


that the elevation pattern is more pronounced in migrant birds, with lowland migrant birds having the longest FIDs (Fig. 3). However, neither of these predictors featured in any top model set, and indeed the best model including elevation performed substantially worse than the top model (delta $\mathrm{AICc}=5.842$ ).

In total, the fixed effects in the global model explained $68 \%$ of the variation in FIDs, although starting distance and body mass accounted for the vast majority of that variance (Table 4).

\section{Discussion}

Our best model of FID featured positive effects of starting distance, body mass and group status and a negative effect of human density-effects which have been reported in comparative analyses from all or most other continents and localities for which data are available. Starting distance appears universally and positively related to avian FID perhaps because it permits birds to judge risk and 'flush early and avoid the rush' (Blumstein 2003, 2010), or because it is a methodological artefact (Dumont et al. 2012), or both. Body mass is usually positively related to avian FID (e.g. Møller et al. 2014), although a comparative analysis of tropical east African birds recently revealed a slightly negative (though non-significant) effect of body mass on FID (Weston et al. 2021). Sri Lankan birds in groups had longer FIDs than when they were alone, which aligns with general patterns observed (Morelli et al. 2019) and is predicted from the benefits of anti-predator vigilance associated with occurring in groups (but see Tätte et al. 2019). We sampled birds in single-species flocks, and note that the prominence of mixed species flocks among Sri Lankan forest birds warrants further investigation of their FID (Mammides et al. 2018; Linley et al. 2019). We confirm the apparently universal influence of human density on avian FID, whereby shorter FIDs occur in areas with more people (Samia et al. 2015a). Our measure of local human density may have utility in contexts (common in many parts of the world) where the urban-rural distinction does not clearly apply. High human densities occur in rural areas in many parts of the world, especially in Asia (Qadeer 2000),
Fig. 1 Relationship between flight-initiation distance and $\mathbf{A}$ body mass, $\mathbf{B}$ group status, $\mathbf{C}$ human population density and D time of day for Sri Lankan birds. Flight-initiation distance (y-axes), mass and human population density are shown on a log scale (tick marks are labelled with untransformed values). Panels A, C and D show linear regression lines and $95 \%$ confidence interval in red. The boxplot in panel B shows the median (central line), interquartile range (box area) and predominant range minus outliers (whiskers), with raw data overlaid
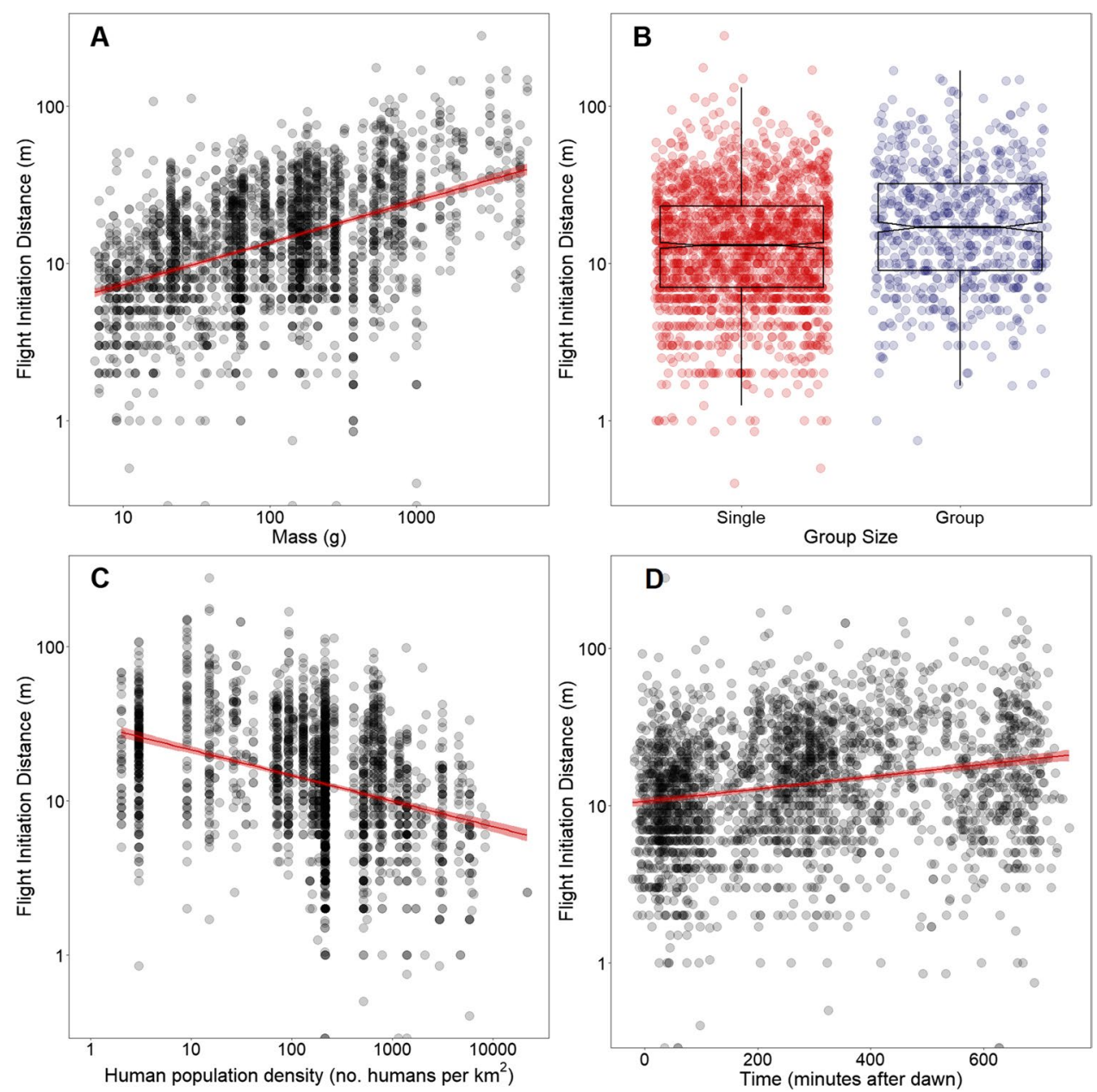
meaning that the classic urban-rural distinction does not necessarily reflect the prevailing human regime experienced by birds. Urban and rural areas differ in aspects other than human activity (e.g. predator regimes, structural complexity, resources) which potentially confound comparisons of FIDs between urban and rural environments (Weston et al. 2012). Indeed, in studies within homogenous forest habitat, avian FIDs are lower in those areas with more humans, suggesting exposure to humans does influence FIDs independently of other confounding effects (Bötsch et al. 2018). Our use of the continuous measure of human population density, combined with our random effect of location, also suggests that birds exhibit shorter FIDs in relation to being exposed to more humans, regardless of whether or not areas are rural or urban. The effects of starting distance, body mass, group status and human density which we report are unremarkable, given that they have been described from similar studies on other avifaunas. However, we confirm for the first time their existence among Sri Lankan birds, and to our knowledge, our study represents the most comprehensive assessment of possible predictors of FID for a tropical island's avifauna.

The interaction between body mass and human population density also featured in four out of the 12 top models (Table 2), and was statistically significant (Table 3 ). This interaction indicated that the decline in FID with increasing exposure to humans is moderated by body size, with larger birds showing a steeper decline, such that, in areas of high human population density, the difference in FIDs between large and small birds is less pronounced. A broadly similar pattern has been reported between continents. Avian FIDs increase with body mass for Australian birds (comparatively sparsely populated) but not for African birds (densely populated) (Weston et al. 2021). The pattern we report is consistent with the idea that larger birds have the capacity to tolerate people more readily (Samia et al. 2015a), perhaps because of greater cognition associated with relatively larger brains (Samia et al. 2015b), higher costs associated with leaving a resource patch (Glover et al. 2011), or other as yet unidentified factors.

We also report two further effects which apply to Sri Lankan birds and which have, to date, been understudied: time of day and elevation. FIDs showed a very weak tendency to increase as the day progressed (this effect featured in seven of the top 12 models, but was minimal and not statistically significant). Links between time of day and FID have, to our knowledge, only previously been identified in only a couple of studies, and with contrasting patterns: Burger and Gochfeld (1991) found shorter FIDs later in the day in Indian birds, which they ascribed to greater human activity at those times. By contrast, Ferguson et al. (2019) for a single species of nectarivore argued that shorter FIDs earlier in the day were related to energetic constraints after nocturnal fasting. The extent to which this explanation applies to Sri Lankan birds is unclear, but it seems unlikely given Burger and Gochfeld's
(1991) results. Given the reported effect was non-significant, and the relationship may even be non-linear (see Fig. 1D), we refrain from further inference; however, further investigation of the time of day effect across birds in different climates and with different life histories seems warranted.

The global model indicated a significant effect of shorter FIDs occurring in highland birds. The only other study (a single-species), study of elevation and FID in birds, predicted shorter FIDs at higher elevations, in line with shorter FIDs which occur at higher latitudes, and the similar patterns of seasonality, climate and predator density that covary between latitude and elevation (Andrade and Blumstein 2020). Our results align with this prediction. Contrary to Andrade and Blumstein's (2020) prediction, they reported longer FIDs at higher elevations for their single study species. Thus, this study provides the first confirmatory comparative evidence for the proposed elevational effect. Furthermore, a significant interaction effect with migratory behaviour was also apparent in the global model, such that the longer FIDs of lowland birds are more pronounced for migrant species (Fig. 3). Other studies have documented that migrants have longer FIDs in both temperate (Mikula et al. 2018a, b) and tropical (Burger and Gochfeld 1991; Weston et al. 2021)

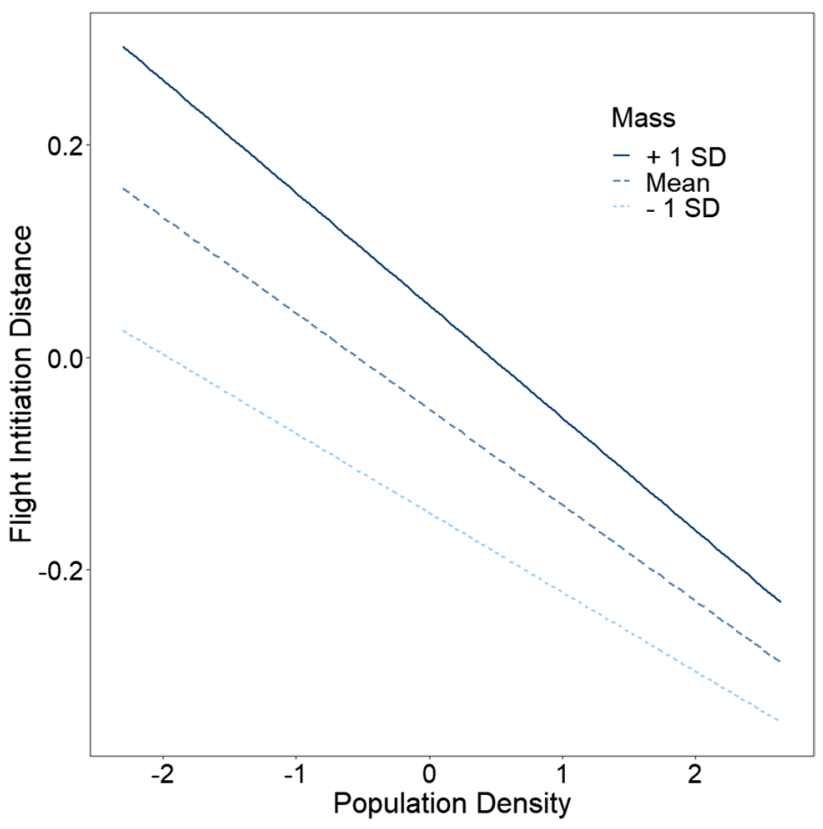

Fig. 2 Interaction effect of body mass and human population density on flight-initiation distances of Sri Lankan birds. Birds with greater mass generally have longer flight-initiation distances, but show a steeper reduction in flight-initiation distances in response to increased human population density. The three lines show the predicted linear relationship between flight-initiation distance (log-transformed and $z$-standardised) and human population density for averaged sized birds (mean mass), larger birds (mass one standard deviation above the mean) and smaller birds (mass one standard deviation below the mean) 
Table 4 Full global generalised linear mixed model predicting flight-initiation distance (FID) in Sri Lankan bird species. FID and all continuous predictors were $z$-standardised. Mean estimate and 95\% CI refer to the mean and $95 \%$ credible interval of the Bayesian posterior distribution obtained using MCMCglmm. Estimates are expressed relative to birds in open-and-closed habitats, in groups (surrounded by other individuals), and with cooperative breeding, altricial development, aquatic carnivore diet, partly migratory behaviour and at highland elevation. $P$ values show the proportion of the posterior distribution estimated to cross zero. Model marginal $R^{2}=0.68$, conditional $R^{2}=0.74, \lambda=0.07$

\begin{tabular}{|c|c|c|c|c|}
\hline Random effects & Variance & & & \\
\hline Phylogeny & 0.021 & & & \\
\hline Species & 0.010 & & & \\
\hline Location & 0.028 & & & \\
\hline Residual & 0.245 & & & \\
\hline Fixed effects & Post mean & Lower CI & Upper CI & $\mathrm{P}$ \\
\hline Intercept & -0.031 & -0.318 & 0.304 & 0.818 \\
\hline Starting distance & 0.581 & 0.523 & 0.632 & $<0.001$ \\
\hline Habitat (closed) & 0.085 & -0.051 & 0.200 & 0.206 \\
\hline Habitat (open) & 0.066 & -0.037 & 0.157 & 0.178 \\
\hline Mass & 0.107 & 0.051 & 0.161 & 0.002 \\
\hline Population density & -0.114 & -0.165 & -0.073 & $<0.001$ \\
\hline Date & 0.005 & -0.024 & 0.036 & 0.708 \\
\hline Time & 0.020 & -0.010 & 0.049 & 0.144 \\
\hline Group status (single) & -0.054 & -0.106 & -0.007 & 0.022 \\
\hline Breeding (solitary) & 0.032 & -0.061 & 0.135 & 0.536 \\
\hline Development (precocial) & 0.092 & -0.098 & 0.247 & 0.290 \\
\hline Diet (benthic) & 0.026 & -0.171 & 0.265 & 0.838 \\
\hline Diet (carnivore) & 0.011 & -0.126 & 0.143 & 0.852 \\
\hline Diet (frugivore) & -0.042 & -0.327 & 0.233 & 0.764 \\
\hline Diet (generalist) & -0.232 & -0.464 & -0.006 & 0.054 \\
\hline Diet (generalist granivore) & -0.093 & -0.250 & 0.081 & 0.282 \\
\hline Diet (generalist insectivore) & -0.161 & -0.327 & 0.017 & 0.072 \\
\hline Diet (insectivore) & -0.138 & -0.304 & 0.038 & 0.120 \\
\hline Clutch size & 0.021 & -0.017 & 0.056 & 0.256 \\
\hline Migratory behaviour (migrant) & 0.209 & -0.078 & 0.451 & 0.130 \\
\hline Migratory behaviour (resident) & -0.154 & -0.345 & 0.029 & 0.098 \\
\hline Elevation (lowland) & 0.256 & 0.108 & 0.413 & 0.004 \\
\hline StDist: habitat (closed) & 0.027 & -0.064 & 0.119 & 0.562 \\
\hline StDist: habitat (open) & 0.034 & -0.027 & 0.096 & 0.262 \\
\hline Mass: population density & -0.037 & -0.059 & -0.012 & 0.002 \\
\hline Migrat. behav. (migrant): elev. (lowland) & -0.253 & -0.470 & -0.052 & 0.016 \\
\hline
\end{tabular}

environments, possibly because they are less regularly exposed to (and hence habituated to) humans, or because, with their longer and more pointed wings (Lockwood et al. 1998), the costs of escape flights are lower for migrants. That the difference between migrants and residents is less pronounced at highland studies might possibly be a consequence of the physiological limitations of mounting energy-intensive behaviours at higher elevations (Barve et al. 2016).

It is curious that, despite these apparently significant patterns, neither elevation nor the migration $\times$ elevation interaction featured in any top models from our model selection procedure. This is not due to any confounding effect with other fixed predictors (variance inflation factors for both elevation and migratory behaviour are low). However, we note that our sampling from highland locations was limited ( $N=162-6.3 \%$ of our observations), and elevation is inevitably somewhat confounded with our random effect of location. Given the lack of model support, therefore, as with time of day, we must be circumspect in interpretation of the effects of elevation and migration. Ideally, more systematic sampling from across a greater range of elevations would be informative in future studies (we sampled only highland and lowland Sri Lankan locations, with no sampling at intermediate elevations).

A range of other variables did not feature in our best models (date, breeding system, habitat, clutch size, developmental mode, diet). All of these have been shown, or linked, with avian FIDs in other studies from other, usually temperate and continental areas (see references in Table 1). These effects therefore appear more localised, and further studies could confirm if they exist in other tropical localities. We note that seasonality is fundamentally different in tropical ecosystems, and that tropical birds may not experience seasonal food shortages (Bender et al. 2017). 


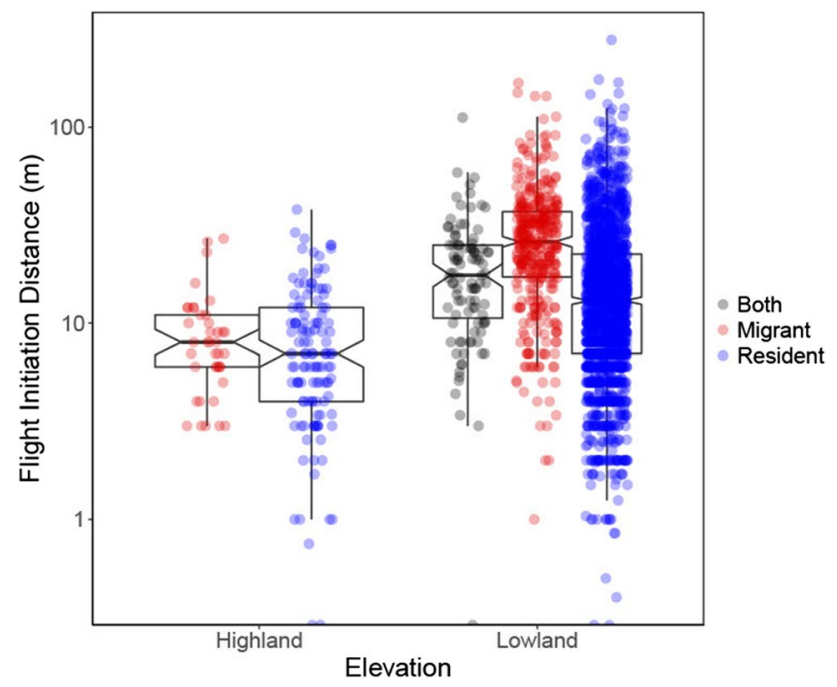

Fig. 3 Interaction effect of elevation (lowland or highland) and migratory status (resident, migratory or partial migrant) on flightinitiation distances of Sri Lankan birds. Lowland birds tend to have longer flight-initiation distances, and this effect is augmented in migratory species. Although these effects are significant in the global model, they did not feature in the list of top models from the model selection analysis. Boxplot shows the median (central line), interquartile range (box area) and predominant range minus outliers (whiskers), with raw data overlaid

Finally, escape distances can inform management of human disturbance (Guay et al. 2016). In Sri Lanka, nature and wildlife tourism is common, and challenges exist in ensuring these ventures are sustainable (Fernando and Shariff 2017). Some ecotourism activities are more disturbing, to some species, than the pedestrian approach we employed here (Radkovic et al. 2019; Slater et al. 2019). However, our FID data offer a guide for suitable buffers, albeit those which require refinement and adaptive implementation (Guay et al. 2016).

Supplementary Information The online version contains supplementary material available at https://doi.org/10.1007/s00265-022-03138-0.

Acknowledgements We thank the people of Sri Lanka. Thanks to Allison Piper, Chaminda Mahanayake, Upali Ekanayake, Chathuranga Dharmarathne, Chinthaka Pradeep Weerasinghe, Anthony Rendall and Dinush Hettiarachchi. We also thank the associate editor and reviewers for their constructive criticisms on earlier versions of this manuscript. Modest amounts of data were collected by Deakin University students of SLE301XOS and SLE225 (notably Hayley Forster, Mike Hayes, Caitlin Slater). S. Seneviratne kindly accessed banding data from Field Ornithological Group of Sri Lanka (FOGSL) data.

Author contribution This study was conceived by KE, JJG, MAW and MRES. Data were collected by KE, JJG, MAW, DRV, UTA and CF. Logistics and permits: KR, MAW, KE, JJG and UTA. Analysis and write up: AM, MRES and MAW.
Funding Open Access funding enabled and organized by CAUL and its Member Institutions. Some trips of MAW were partly funded by New Colombo Plan (Department of Foreign Affairs and Trade, Australian Government) and Deakin University's Faculty of Science, Engineering and the Built Environment and School of Life and Environmental Sciences grants for international collaboration.

\section{Declarations}

Ethics approval Animal ethics approvals were obtained (Deakin University Animal Ethics Committee Permits B32-2012, B11-2015, B102018) as was a Sri Lankan Department of Wildlife Conservation Permit (WL/3/2/61/15; K. Ranawana). All applicable international, national and institutional guidelines for the use of animals were followed.

Conflict of interest The authors declare no competing interests.

Open Access This article is licensed under a Creative Commons Attribution 4.0 International License, which permits use, sharing, adaptation, distribution and reproduction in any medium or format, as long as you give appropriate credit to the original author(s) and the source, provide a link to the Creative Commons licence, and indicate if changes were made. The images or other third party material in this article are included in the article's Creative Commons licence, unless indicated otherwise in a credit line to the material. If material is not included in the article's Creative Commons licence and your intended use is not permitted by statutory regulation or exceeds the permitted use, you will need to obtain permission directly from the copyright holder. To view a copy of this licence, visit http://creativecommons.org/licenses/by/4.0/.

\section{References}

Abeyarama DK, Seneviratne SS (2017) Evolutionary distinctness of Important Bird Areas (IBAs) of Sri Lanka: do the species-rich wet zone forests safeguard Sri Lanka's genetic heritage? Ceylon J Sci 46:89-99. https://doi.org/10.4038/cjs.v46i5.7456

Andrade M, Blumstein DT (2020) Anti-predator behavior along elevational and latitudinal gradients in dark-eyed juncos. Curr Zool 66:239-245. https://doi.org/10.1093/cz/zoz046

Bartoń K (2020) MuMIn: Multi-model inference. R package version 1.43.17, https://CRAN.R-project.org/package $=$ MuMIn

Barve S, Dhondt AA, Mathur VB, Cheviron ZA (2016) Life-history characteristics influence physiological strategies to cope with hypoxia in Himalayan birds. Proc R Soc B 283:20162201. https:// doi.org/10.1098/rspb.2016.2201

Bender IM, Kissling WD, Böhning-Gaese K, HensenKühn KI, Wiegand T, Dehling DM, Schleuning M (2017) Functionally specialised birds respond flexibly to seasonal changes in fruit availability. J Anim Ecol 86:800-811. https://doi.org/10.1111/ 1365.2656.12683

Bjørvik LM, Dale S, Hermansen GH, Munishi PK, Moe SR (2015) Bird flight-initiation distances in relation to distance from human settlements in a Tanzanian floodplain habitat. J Ornithol 156:239246. https://doi.org/10.1007/s10336-014-1121-1

Blumstein DT (2003) Flight-initiation distance in birds is dependent on intruder starting distance. J Wildlife Manage 67:852-857. https:// doi.org/10.2307/3802692

Blumstein DT (2006) Developing an evolutionary ecology of fear: how life history and natural history traits affect disturbance tolerance in birds. Anim Behav 71:389-399. https://doi.org/10.1016/j.anbeh av.2005.05.010 
Blumstein DT (2010) Flush early and avoid the rush: a general rule of antipredator behavior? Behav Ecol 21:440-442. https://doi.org/ 10.1093/beheco/arq030

Blumstein DT (2019) What chasing birds can teach us about predation risk effects: past insights and future directions. J Ornithol 160:587-592. https://doi.org/10.1007/s10336-019-01634-1

Bötsch Y, Gugelmann S, Tablado Z, Jenni L (2018) Effect of human recreation on bird anti-predatory response. PeerJ 6:e5093. https:// doi.org/10.7717/peerj.5093

Burger J, Gochfeld M (1991) Human distance and birds: tolerance and response distances of resident and migrant species in India. Environ Conserv 18:158-165

Burnham KP, Anderson DR (2002) Model selection and multimodel inference: a practical information-theoretic approach, 2nd edn. Springer-Verlag, New York

Cabrera D, Andres D, McLoughlin PD, Debeffe L, Medill SA, Wilson AJ, Poissant J (2017) Island tameness and the repeatability of flight-initiation distance in a large herbivore. Can J Zool 95:771778. https://doi.org/10.1139/cjz-2016-0305

Cooper WE, Pyron RA, Garland T (2014) Island tameness: living on islands reduces flight-initiation distance. Proc R Soc B 281:20133019. https://doi.org/10.1098/rspb.2013.3019

d'Hauteserre AM (2016) Ecotourism an option in small island destinations? Tour Hosp Res 16:72-87. https://doi.org/10.1177/14673 58415600209

Díaz M, Møller AP, Flensted-Jensen E, Grim T, Ibáñez-Álamo JD, Jokimäki J, Markó G, Tryjanowski P (2013) The geography of fear: a latitudinal gradient in anti-predator escape distances of birds across Europe. PLoS ONE 8:e64634. https://doi.org/10. 1371/journal.pone.0064634

Dumont F, Pasquaretta C, Réale D, Bogliani G, von Hardenberg A (2012) Flight-initiation distance and starting distance: biological effect or mathematical artefact? Ethol 118:1051-1062. https://doi. org/10.1111/eth.12006

Dunning JB (2007) CRC handbook of avian body masses. CRC Press, Boca Raton

Ekanayake KB, Gnanapragasam JJ, Ranawana K, Vidanapathirana DR, Abeyawardhana UT, Fernando C, McQueen A, Weston MA, Symonds MRE (2022) Data associated with "Ecological and environmental predictors of escape among birds on a large tropical island". Dryad, Dataset. https://doi.org/10.5061/dryad.b2rbnzsh4

Ferguson SM, Gilson LN, Bateman PW (2019) Look at the time: diel variation in the flight-initiation distance of a nectarivorous bird. Behav Ecol Sociobiol 73:147. https://doi.org/10.1007/ s00265-019-2757-x

Fernando SLJ, Shariff NM (2017) Wetland ecotourism in Sri Lanka: issues and challenges. Geografia 9:99-105

Garamszegi LZ, Møller AP (2010) Effects of sample size and intraspecific variation in phylogenetic comparative studies: a meta-analytic review. Biol Rev 85:797-805. https://doi.org/10.1111/j.1469185X.2010.00126.x

Glover HK, Weston MA, Maguire GS, Miller KK, Christie BA (2011) Towards ecologically meaningful and socially acceptable buffers: response distances of shorebirds in Victoria, Australia, to human disturbance. Landscape Urban Plan 103:326-334. https://doi.org/ 10.1016/j.landurbanplan.2011.08.006

Gnanapragasam JJ, Ekanayake KB, Ranawana K, Symonds MRE, Weston MA (2021) Civil war is associated with longer escape distances among Sri Lankan birds. Am Nat 198:653-659. https:// doi.org/10.1086/716660

Gonzalez AD, Matta NE, Ellis VA, Miller ET, Ricklefs RE, Gutierrez HR (2014) Mixed species flock, nest height, and elevation partially explain avian haemoparasite prevalence in Colombia. PLoS ONE 9(6):e100695. https://doi.org/10.1371/journal.pone.0100695
Gotanda K (2020) Human influences on antipredator behaviour in Darwin's finches. J Anim Ecol 89:614-622. https://doi.org/10. 1111/1365-2656.13127

Guay PJ, McLeod EM, Cross R, Formby AJ, Maldonado SP, Stafford-Bell RE, St-James-Turner ZN, Robinson RW, Mulder RA, Weston MA (2013) Observer effects occur when estimating alert but not flight-initiation distances. Wildlife Res 40:289-293. https://doi.org/10.1071/WR13013

Guay PJ, van Dongen WF, Robinson RW, Blumstein DT, Weston MA (2016) AvianBuffer: an interactive tool for characterising and managing wildlife fear responses. Ambio 45:841-851. https:// doi.org/10.1007/s13280-016-0779-4

Hackett SJ, Kimball RT, Reddy S et al (2008) A phylogenomic study of birds reveals their evolutionary history. Science 320:17631768. https://doi.org/10.1126/science.1157704

Hadfield JD (2010) MCMC methods for multi-response generalized linear mixed models: The MCMCglmm R package. J Stat Soft 33:1-22. https://doi.org/10.18637/jss.v033.i02

Handbook of the Birds of the World (2019) Cornell Laboratory of Ornithology, https://birdsoftheworld.org/bow/home Accessed 26 Sep 2019

Humphrey PS, Livezey BC, Siegel-Causey D (1987) Tameness of birds of the Falkland Islands: an index and preliminary results. Bird Behav 7:67-72. https://doi.org/10.3727/015613887791918114

Jetz W, Thomas GH, Joy JB, Hartmann K, Mooers AO (2012) The global diversity of birds in space and time. Nature 491:444-448. https://doi.org/10.1038/nature11631

Linley GD, Guay PJ, Weston MA (2020) Are disturbance separation distances derived from single species applicable to mixedspecies shorebird flocks? Wildlife Res 46:719-723. https://doi. org/10.1071/WR18198

Livezey KB, Blumstein DT (2016) "Shortest-distance" method is more accurate than conventional method in estimating flightinitiation distances for close perched birds. J Ornithol 157:923925. https://doi.org/10.1007/s10336-106-1337-3

Lockwood R, Swaddle JP, Rayner JMV (1998) Avian wingtip shape reconsidered: wingtip shape indices and morphological adaptations to migration. J Avian Biol 29:273-292

Lomas SC, Whisson DA, Maguire GS, Tan LX, Guay P-J, Weston MA (2016) The influence of cover on nesting Red-capped Plovers: a trade-off between thermoregulation and predation risk? Victorian Nat 131:115-127

Mammides C, Chen J, Goodale UM, Kotagama SW, Goodale E (2018) Measurement of species associations in mixed-species bird flocks across environmental and human disturbance gradients. Ecosphere 9:e02324. https://doi.org/10.1002/ecs2.2324

Mayer M, Natusch D, Frank S (2019) Water body type and group size affect the flight initiation distance of European waterbirds. PLoS ONE 14:e0219845. https://doi.org/10.1371/journal.pone.0219845

McQueen A, Delhey K, Szecsenyi B, Crino OL, Roast MJ, Peters A (2021) Physiological costs and age constraints of a sexual ornament: an experimental study in a wild bird. Behav Ecol 32:327338. https://doi.org/10.1093/beheco/araa143

Mikula P, Díaz M, Albrecht T, Jokimäki J, Kaisanlahti-Jokimäki ML, Kroitero G, Møller AP, Tryjanowski P, Yosef R, Hromada M (2018) Adjusting risk-taking to the annual cycle of long-distance migratory birds. Sci Rep 8:13989. https://doi.org/10.1038/ s41598-018-32252-1

Mikula P, Díaz M, Møller AP, Albrecht T, Tryjanowski P, Hromada M (2018) Migratory and resident waders differ in risk taking on the wintering grounds. Behav Process 157:309-314. https://doi.org/ 10.1016/j.beproc.2018.07.020

Moiron M, Mathot KJ, Dingemanse NJ (2018) To eat and not be eaten: diurnal mass gain and foraging strategies in wintering great tits. Proc R Soc B 285:20172868. https://doi.org/10.1098/rspb.2017.2868 
Møller AP (2014) Life history predation and flight-initiation distance in a migratory bird. J Evol Biol 27:1105-1113. https://doi.org/ 10.1111/jeb.12399

Møller AP, Liang W (2013) Tropical birds take small risks. Behav Ecol 24:267-272. https://doi.org/10.1093/beheco/ars163

Møller AP, Samia DSM, Weston MA, Guay PJ, Blumstein DT (2014) American exceptionalism: population trends and flight-initiation distances in birds. PLoS ONE 9:e107883. https://doi.org/10.1371/ journal.pone.0107883

Morelli F, Benedetti Y, Díaz M et al (2019) Contagious fear: escape behavior increases with flock size in European gregarious birds. Ecol Evol 9:6096-6104. https://doi.org/10.1002/ece3.5193

Nakagawa S, Schielzeth H (2013) A general and simple method for obtaining $\mathrm{R}^{2}$ from generalized linear mixed-effects models. Methods Ecol Evol 4:133-142. https://doi.org/10.1111/j.2041-210x. 2012.00261.x

Newton I (2003) Speciation and biogeography of birds. Academic Press, London

Osorio-Beristain M, Rodríguez Á, Martínez-Garza C, Alcalá RE (2018) Relating flight-initiation distance in birds to tropical dry forest restoration. Zoologia 35:e12642. https://doi.org/10.3897/ zoologia.35.e12642

Pagel M (1999) Inferring the historical patterns of biological evolution. Nature 401:877-884. https://doi.org/10.1038/44766

Piratelli AJ, Favoretto GR, Maximiano MF (2015) Factors affecting escape distance in birds. Zoologia 32:438-444. https://doi.org/ 10.1590/s1984-46702015000600002

Poddubnaya N, Korotkova T, Vanicheva P (2019) Increasing corvid tolerance to humans in urban ecosystems with increasing latitude. Biol Commun 64:252-259. https://doi.org/10.21638/spbu03.2019.404

Qadeer MA (2000) Ruralopolises: the spatial organisation and residential land economy of high-density rural regions in South Asia. Urban Stud 37:1583-1603. https://doi.org/10.1080/00420980020080271

Radkovic AZ, Van Dongen WF, Kirao L, Guay PJ, Weston MA (2019) Birdwatchers evoke longer escape distances than pedestrians in some African birds. J Ecotourism 18:100-106. https://doi.org/10. 1080/14724049.2017.1372765

Samia DSM, Blumstein DT (2014) Phi Index: A new metric to test the flush early and avoid the rush hypothesis. PLoS ONE 11:e113134. https://doi.org/10.1371/journal.pone.0113134

Samia DSM, Møller AP, Blumstein DT (2015) Brain size as a driver of avian escape strategy. Sci Rep 5:11913. https://doi.org/10.1038/ srep11913

Samia DSM, Nakagawa S, Nomura F, Rangel TF, Blumstein DT (2015) Increased tolerance to humans among disturbed wildlife. Nat Commun 6:8877. https://doi.org/10.1038/ncomms9877
Schliep KP (2011) phangorn: phylogenetic analysis in R. Bioinformatics 27:592-593. https://doi.org/10.1093/bioinformatics/btq706

Simpson RK, Johnson MA, Murphy TG (2015) Migration and the evolution of sexual dichromatism: evolutionary loss of female coloration with migration among wood-warblers. Proc R Soc B 282:20150375. https://doi.org/10.1098/rspb.2015.0375

Slater C, Cam G, Qi Y, Liu Y, Guay PJ, Weston MA (2019) Camera shy? Motivations attitudes and beliefs of bird photographers and species-specific avian responses to their activities. Biol Conserv 237:327-337. https://doi.org/10.1016/j.biocon.2019.07.016

St Clair JJ, García-Peña GE, Woods RW, Székely T (2010) Presence of mammalian predators decreases tolerance to human disturbance in a breeding shorebird. Behav Ecol 21:1285-1292. https://doi. org/10.1093/beheco.arq144

Tätte K, Ibáñez-Álamo JD, Markó G, Mänd R, Møller AP (2019) Antipredator function of vigilance re-examined: vigilant birds delay escape. Anim Behav 156:97-110. https://doi.org/10.1016/janbe hav.2019.08.010

Thibault M, Weston MA, Ravache A, Vidal E (2020) Flight-initiation response reflects short-and long-term human visits to remote islets. Ibis 162:1082-1087. https://doi.org/10.1111/ibi.12810

Tryjanowski P, Kosicki JZ, Hromada M, Mikula P (2020) The emergence of tolerance of human disturbance in Neotropical birds. J Tropical Ecol 36:1-5. https://doi.org/10.1017/S02664674190002 82

Warakagoda D, Inski C, Inski T, Grimmett R (2020) Birds of Sri Lanka. Bloomsbury Publishing, London

Weston MA, Ju YK, Guay PJ, Naismith C (2018) A test of the "Leave Early and Avoid Detection"(LEAD) hypothesis for passive nest defenders. Wilson J Ornithol 130:1011-1013. https://doi.org/10. 1676/17-00038.1

Weston MA, McLeod EM, Blumstein DT, Guay PJ (2012) A review of flight-initiation distances and their application to managing disturbance to Australian birds. Emu 112:269-286. https://doi. org/10.1071/MU12026

Weston MA, Radkovic A, Kirao L, Guay P-J, Van Dongen WFD, Malaki P, Blumstein DT, Symonds MRE (2021) Differences in flight initiation distances between African and Australian birds. Anim Behav 179:235-245. https://doi.org/10.1016/j.anbehav. 2021.07.008

Publisher's note Springer Nature remains neutral with regard to jurisdictional claims in published maps and institutional affiliations.

\section{Authors and Affiliations}

\section{Kasun B. Ekanayake ${ }^{1,2}$. Jonathan Jebamaithran Gnanapragasam ${ }^{1} \cdot$ Kithsiri Ranawana $^{3}$. Dulan Ranga Vidanapathirana ${ }^{4}$. U. Tiran Abeyawardhana ${ }^{5}$. Chandima Fernando ${ }^{6} \cdot$ Alexandra McQueen $^{1}$ (D) Michael A. Weston ${ }^{1}$ (1) . Matthew R. E. Symonds ${ }^{1}$ (1)}

1 Centre for Integrative Ecology, School of Life and Environmental Sciences, Deakin University, 221 Burwood Highway, Burwood, VIC 3125, Australia

2 BirdLife Australia, Suite 2-05, The Green Building, 60 Leicester Street, Carlton, VIC 3053, Australia

3 Department of Zoology, University of Peradeniya, Galaha Rd 20400, Sri Lanka
4 Herpetological Foundation of Sri Lanka, 31/5, Alwis Town, Hendala, Wattala, Sri Lanka

5182 Piyarathanarama Place, Dehiwala, Sri Lanka

6 Field Ornithology Group of Sri Lanka, Department of Zoology and Environment Sciences, University of Colombo, Colombo, Sri Lanka 